Journal of Applied Pharmaceutical Science Vol. 5 (09), pp. 089-096, September, 2015

Available online at http://www.japsonline.com

DOI: 10.7324/JAPS.2015.50916

ISSN 2231-3354 (cc) BY-NC-SA

\title{
Influence of different types of lactose on powder flow and tablets dissolution
}

\author{
Karen Velázquez-González, Eduardo Ramírez-Flores, Leopoldo Villafuerte-Robles* \\ Department of Pharmacy, National School of Biological Sciences, National Polytechnic Institute of Mexico, D. F., Mexico.
}

\begin{tabular}{|c|c|}
\hline ARTICLE INFO & ABSTRACT \\
\hline Article history: & \multirow{10}{*}{$\begin{array}{l}\text { The objective of this study was the evaluation of different types of lactose on the powders flow properties and } \\
\text { dissolution of tablets of formulations with captopril and amoxicillin. Data of powders flow rate, compressibility } \\
\text { index and dissolution profiles of tablets are presented. The powders flow rate showed higher sensitivity to small } \\
\text { changes in their properties, compared to compressibility index. SuperTabs } 21 \mathrm{AN} \text { and } 24 \mathrm{AN} \text { flow at least } 20 \\
\text { times faster than Lactopress and lactose NF. Lubrication increases the flow rate, maintaining the observed } \\
\text { comparative differences. Dilution of lactoses with } 50 \% \text { captopril or amoxicillin reduces drastically the powder } \\
\text { flow, producing also an equalizing effect. The greater flowability of SuperTabs, compared to other types of } \\
\text { lactose, practically disappears. Dissolution of lubricated and unlubricated lactose tablets show a much faster } \\
\text { dissolution of SuperTab } 21 \mathrm{AN} \text { tablets followed by Lactopress, lactose NF and SuperTab 24AN tablets. Dilution } \\
\text { of lactoses with 50\% captopril displays a quite smaller dissolution rate with a comparative similar behavior as } \\
\text { observed before while dilution with amoxicillin show an equalizing effect of drug dissolution with minor } \\
\text { differences between lactoses. The effect of lactose excipients on dissolution is attributed in a greater extent to } \\
\text { mechanical properties of their tablets than to differences in solubility and dissolution. }\end{array}$} \\
\hline Received on: $11 / 06 / 2015$ & \\
\hline Revised on: & \\
\hline Accepted on: & \\
\hline Available online: $27 / 09 / 2015$ & \\
\hline Key words: & \\
\hline Compressibility index, & \\
\hline Powder flowability, & \\
\hline Dissolution profile, excipient & \\
\hline $\begin{array}{l}\text { functionality, Amoxicillin, } \\
\text { Captopril. }\end{array}$ & \\
\hline
\end{tabular}

\section{INTRODUCTION}

Direct compression is an economical and flexible technology that relates to the growth in the pharmaceutical market of the excipients and equipment designed according to the state of the art of science and technology. The most important characteristics required in materials used in direct compression are compactibility and flowability. Given this, carriers can be identify that provide fluidity and homogeneity of mixtures, compactibility and the desired dissolution in the manufactured products. The judicious selection of excipients can improve the tableting properties of mixtures used in direct compression (Emshanova, 2008). The effects of pharmaceutical excipients on the quality of medicinal products must be studied before the development of a product start, verifying compliance with production standards, investigating their influence on the physical, pharmacological and microbiological characteristics of the products, and their influence on therapeutic efficacy and

\footnotetext{
* Corresponding Author

Leopoldo Villafuerte-Robles, Department of Pharmacy, National School of Biological Sciences, National Polytechnic Institute of Mexico, D. F., Mexico.Email: lvillaro@encb.ipn.mx
}

safety of formulations, the release of active ingredient, bioavailability, etc. (Aleeva et al., 2009). Flowability is one of the most important factors for the development of pharmaceutical dosage forms. Insufficient flow properties of solid products can cause serious problems during processing, for example, compression, filling and transportation. It is essential to evaluate flow properties as early as possible in the development, so that an optimal formulation can be quickly identified. The flowability of a powder determines its processing properties with respect to manufacturing a variety of solid dosage forms. Poor powder flow often requires significant changes in a formulation that otherwise would be satisfactory (Podczeck and Miah, 1996). The flowability of powders is determined either directly by kinetic and dynamic methods, or by indirect methods. Direct methods include the flow rate from a hopper. Moreover, they have also been described direct techniques such as the study of the fall by sliding of powders. Indirect methods include the determination of the angle of repose, of the shear cell and the measurement of the critical orifice diameter. It has also been used as an indirect method of assessing powder flow the determination of the ratio of the densities of the poured and tapped powder, the powder compressibility indexes of Hausner and Carr, which have a correlation with the flowability. 
However, the results achieved by indirect methods are often difficult to connect with the real behavior of powders during processing (Räsänen et al., 2003). The powder density depends on the particle packing and the density changes as powder is consolidated. The degree of consolidation is characteristic for each powder and the ratio of the bulk and tapped densities is correlated with the interparticle friction. A dynamic method can be as simple as measuring the rate at which the powder is discharged from a hopper. Typically, a valve is open for the complete discharge of the powder from the hopper, recording the time to calculate the flow rate of the powder mass.

The behavior of a powder and that of the matter in any other state shows some differences. A powder can expand or contract in a limited interval by the change in porosity and remain subsequently in that expanded or contracted state. Furthermore, although the shear forces can deform a powder to make it flow as a viscous liquid, the shear force required to produce the deformation is a function of the load applied perpendicular to the shear plane direction. Consequently, different test methods, which vary in the nature and degree of force application and thus the energy transmission, quantify the macroscopic properties of a powder differently (Lee et al., 2000). Therapeutic efficacy and bioavailability of a drug in a solid dosage form involves its release and dissolution from the formulation to biological fluids and membranes crossing into the systemic circulation prior to reaching the site of action. The release process can be characterized by the dissolution rate of the drug from the particulate solid.

Since it is known that the dissolution has a significant effect on the bioavailability and clinical performance, the dissolution test for solid pharmaceuticals has become one of the most important events in the development and pharmaceutical manufacturing and in the regulatory assessment of product quality (Lee et al., 2008). Initially, the dissolution tests were used to demonstrate that different batches of manufactured products have a similar performance as that of the batch proven clinically. While this approach has been successful in securing to the public the quality of the product has led to a less efficient drug development (Dickinson et al., 2008). Under the outline of quality by design $(\mathrm{QbD})$, the dissolution of drugs from a solid formulation is a tool to understand product performance and to measure the impact of changes in raw materials and manufacturing processes. Various excipients are commonly applied to produce drug delivery systems. These inactive ingredients may influence the interfacial phenomena of the transport system or drug vehicle. Thus, the behavior of the excipients determines both the efficiency and the quality of the pharmaceutical preparation (Dredan et al., 2004).

Lactose is a well known and widely used excipient as a diluent in oral solid dosage forms. There are different grades of commercially available lactose, with different physical properties, which allow selection of the most appropriate for a specific formulation. The shape and size of different types of lactose are different due to their different manufacturing process although chemically they are equal. Published data mentioned various effects of lactose in drug dissolution. The mechanisms of these effects include facilitating the disintegration of the formulation, the formation of solid dispersions and deagglomeration. The effect depends on the quality attributes of the applied lactose (Kubbinga et al., 2014). For instance, addition of lactose with a fine size (3.8 microns) to mixtures containing $20 \%$ of indomethacin and spray dried lactose or lactose monohydrate with a larger particle size (106-250 microns) resulted in a significant increase in the dissolution rates. This was attributed to an increase in dissolution rate constants and to deagglomeration. After 10 minutes, the percentage of dissolved drug from the mixture with lactose monohydrate was $35.0 \pm 3.9 \%$ while it was $25.4 \pm 2.1 \%$ from the mixture with spray-dried lactose (Allahham and Stewart, 2007).

The purpose of this study is the evaluation of different types of lactose on the flow properties of powders and the dissolution profile of two drugs from tablets containing these different types of lactose.

\section{MATERIALS AND METHODS}

Lactose anhydrous NF, batch 1320014992, Lactopress anhydrous, batch: 636524; SuperTab 21AN, batch: 10444192; SuperTab 24AN, batch: 10605538; stearic acid, batch: K32003061; magnesium stearate, batch: D00252. All obtained from Helm-México. The drugs amoxicillin trihydrate batch: MB2433 and captopril batch: 1001934001 were obtained from Química Alkano. The drug and the excipients were used as received.

\section{Compressibility index}

To determine the bulk density of a poured powder it is weighed approximately $30 \mathrm{~g}$ of the corresponding material. The powder is gently poured through a funnel of known diameter to a graduated cylinder of $100 \mathrm{ml}$, which is mounted on a tapper, registering the volume occupied by the powder (volume of the poured powder). The powder in the graduated cylinder is tapped from a height of $1.5 \mathrm{~cm}$, by the tapper set at a constant speed of 50 taps per minute. The tapping of the sample is carried out in cycles of 10 taps. The volume occupied by the powder is recorded, repeating the operation as often as necessary, until obtaining 3 equal consecutive measurements. This is the volume of the tapped powder. These measurements are repeated five times. The powders are sieved through a mesh number 20 after each evaluation. The average of the calculated bulk and tapped density is taken as the bulk density of the poured (Dpp) or tapped powder (Dtp) as applicable. The Compressibility Index is calculated, to judge the rheological properties, according to Equation 1.

$$
C I=\frac{D t p-D p p}{D t p} \times 100
$$

\section{Assessment of the powder flow rate}

A sample of approximately $30 \mathrm{~g}$ is weighed and its flow rate assessed using the device above described, through a glass funnel with an opening of $10 \mathrm{~mm}$ diameter. The sample is gently poured into the funnel whose bottom opening was blocked. While 
unlocked, the tapper starts the movement. The time it takes to move the total powder poured through the funnel is registered. The flow rate is calculated by dividing the sample mass by the time. The assay is repeated 5 times, sieving the powder through a mesh number 20 after each measurement. The average of the five repetitions is taken as the flow rate.

\section{Dissolution tests}

The dissolution of $200 \mathrm{mg}$ tablets made of pure and lubricated lactose, with different proportions of stearic acid, was carried out according to the disintegration test of USP 37-NF 32, without disks. The dissolution time of the tablets was determined as the time necessary for the tablets total dissolution, by visual evaluation. The dissolution test for amoxicillin tablets was made according to USP 37-NF 32, apparatus 2 (Paddle Apparatus) adjusted at $20 \mathrm{rpm}$ and $30^{\circ} \mathrm{C}$. The low temperature and speed of the stirrer was used with the aim of increasing the discrimination capability of the test. The dissolution test was carried out with $200 \mathrm{mg}$ tablets containing 50\% amoxicillin and 50\% lactose, lubricated with $1 \%$ magnesium stearate. The $8 \mathrm{~mm}$ circular flat faced tablets were compacted for $10 \mathrm{~s}$ at a compaction pressure of $108 \mathrm{MPa}$. Three $200 \mathrm{mg}$ tablets were placed in $900 \mathrm{~mL} \mathrm{HCl} 0.1 \mathrm{~N}$ withdrawing samples that were tested in amoxicillin content spectrophotometrically at $272 \mathrm{~nm}$. Dissolution of captopril was carried out using only one tablet placed in the dissolution medium. The captopril dissolved was assessed spectrophotometrically at $208 \mathrm{~nm}$.

\section{RESULTS AND DISCUSSION}

\section{Effect of lactose on drug powder flowability}

Figure 1 shows the powder flow rate of four samples of different types of lactose through an orifice of $10 \mathrm{~mm}$ diameter. The flow rate of SuperTab $21 \mathrm{AN}$ is superior, followed by SuperTab 24AN. SuperTabs display powder flow rates about 20 times greater than Lactose anhydrous NF and Lactopress anhydrous. Among SuperTabs, SuperTab 21 AN shows an about $50 \%$ greater flowability than SuperTab 24AN.The results indicate that both SuperTabs have significant higher flowability than the other chemical identical lactose powders.

Lactose is commonly used to formulate direct compression tablets alongside with a lubricant, because it sticks or adheres to compression tools. Therefore, the flowability of the lubricated excipients and their mixtures was also assessed using the compressibility index and the powder flow through a funnel with a given orifice size. Stearic acid and Magnesium stearate are tablet lubricants but also the most widely used additives to improve the flow properties of powders. The optimum content of the lubricant is supposed to be find when it has formed a complete film around each individual particle. Above the optimal concentration it is possible a drop in flowability. In some cases, it has been observed an improvement in powder flowability of lactose mixed with magnesium stearate only after intensive mechanical processing (Zhou et al., 2009). Cited in literature is the case of GalenIQ 720 and its admixtures with magnesium stearate in different proportions, it was observed that additions of magnesium stearate of $0.4-0.8 \%$ increased its flow rate. Higher proportions of the lubricant no longer increased the powder flow rate but reduced it or maintained it in a given magnitude (FuentesGonzalez and Villafuerte-Robles, 2014).

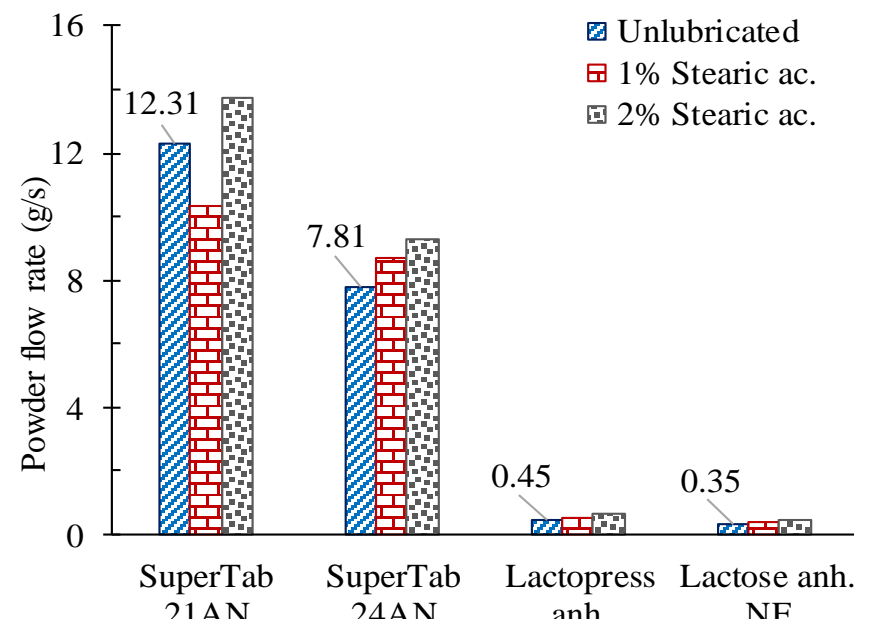

Fig. 1: Powder flow of different types of lactose, unlubricated and lubricated with $1 \%$ and $2 \%$ stearic acid.

As can be seen in Figure 1, there is a general trend to increase the powder flow of all different types of lactose when lubricated with $1 \%$ and $2 \%$ stearic acid. SuperTabs increase their powder flow in about $15 \%$ while Lactopress and Lactose NF do it in about $40 \%$. In spite of this higher increase in powder flow by Lactopress and lactose NF, the powder flow rate of SuperTabs is still about 20 times higher than that of Lactopress and lactose NF. Compressibility is a property that reflects the ability of powders to consolidate when subjected to a given normal stress. The compressibility is defined as the change of volume of the powder under a given normal stress. Although compressibility is not a direct measure of flowability, it provides an indicator as to whether a powder is cohesive or free flowing.

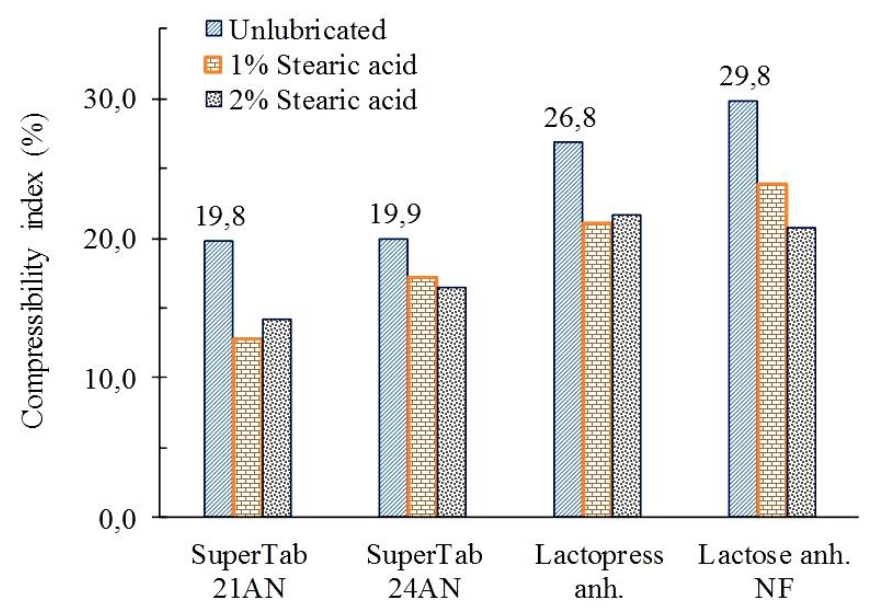

Fig. 2: Compressibility index of different types of lactose unlubricated and lubricated with $1 \%$ and $2 \%$ stearic acid. 
The type of lactose has an important impact on powder compressibility. Figure 2 shows that the two SuperTabs have a lower compressibility than Lactopress and lactose NF. These results reflect the more efficient particle packing of SuperTabs due to their lower cohesivity. The higher compressibility of Lactopress and lactose NF is associated with a high cohesivity of the powders, given by their bulk density and packing structure. The current results are coincident with those reported in literature. Data published by the excipient provider allows the calculation of the compressibility index of SuperTab 24AN as 18.3 while that of SuperTab 21AN is 19.5 (SuperTab 24AN, 2015). These values are similar to those registered in Figure 2. Even if there are also reports of higher values of the compressibility index of SuperTab 21AN (31.7) (Choi et al., 2010).

Once again, SuperTabs show a higher flowability than Lactopress and lactose NF. Moreover, lubrication displays also a decrease in compressibility index of all types of lactose, equivalent to an increase in powder flowability. However, the differences in flowability among different types of lactose determined by means of the compressibility index are quiet smaller than the differences observed by data of the powder flow rate.

SuperTabs have an about $43 \%$ lower compressibility index than Lactopress and lactose NF while the powder flow rate displays an about 20 fold higher flowability of SuperTabs compared to Lactopress and lactose NF. The powder flow rate through an orifice is a considerably more sensitive parameter to identify differences in powders flowability. The powder flow rate displays a wider span of results than the compressibility index.

The effect of application of different types of lactose to a drug is depicted in Figure 3. As can be seen, the different powder flow rate observed by different types of lactose is almost disappeared when mixed with $50 \%$ captopril or $50 \%$ amoxicillin. All types of lactose decrease their powder flow rate. SuperTabs display a more than 20 fold reduction of their powder flow rate while Lactopress and lactose NF display a reduction that remains in the same previous magnitude. SuperTabs still show a something higher flowability only when mixed with amoxicillin.

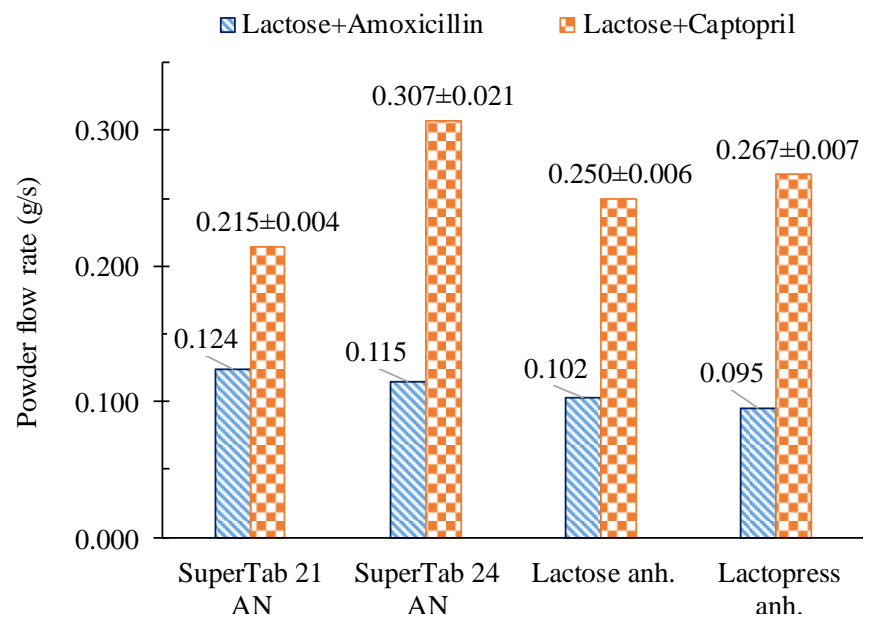

Fig. 3: Powder flow rate of different types of lactose mixed with $50 \%$ amoxicillin or with $50 \%$ captopril, all mixtures containing $1 \%$ lubricant.
The flowability of the mixtures is dominated by the flowability of the drugs at this proportion of the excipients. A dilution of $50 \%$ seems to be too much to maintain the higher original flowabilities of SuperTabs.

As showed by Figure 4, similar results as abovementioned are observed by measurements of compressibility index. Lactose decreases importantly its flowability after mixing with $50 \%$ of amoxicillin or captopril. The use of different types of lactose to improve the flowability of the mentioned drugs has no meaning; no advantage is observed for any one of these different types of lactose.

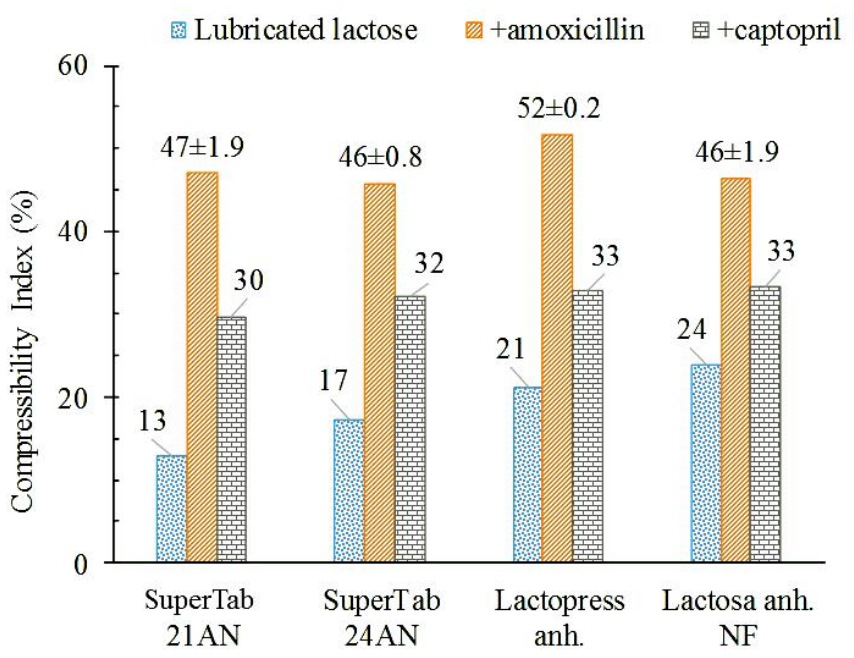

Fig. 4: Compressibility index of different types of pure lactose, lactose mixed with $50 \%$ amoxicillin and with $50 \%$ captopril, all of them containing $1 \%$ lubricant.

A range of compressibility index between 20 and 40 has been considered as suitable or target for a formulation of acetaminophen. Starting with a compressibility index of SuperTab $21 \mathrm{AN}$ of about 24 , after mixing with $10 \%$ acetaminophen the compressibility index increased up to about 27 still being in the target range (DFE pharma, 2015).

In this sense, the compressibility index of formulations of captopril are in the target or acceptable range, however, formulations of amoxicillin are not. The comparison of results obtained with the pure excipients and their admixtures with captopril and amoxicillin allows the expectation that lesser dilutions of the excipients display advantages of SuperTabs over Lactopress and lactose NF.

\section{Effect of lactose on drug dissolution}

Sufficient solubility and dissolution is a prerequisite for effective oral delivery of any therapeutic agent. Various techniques have been used in an attempt to improve the solubility and dissolution rate of drugs including preparation of ordered mixing or physical mixture with hydrosoluble excipients like lactose (AlKhedairy, 2012).

The solubility of diluents in tablets affects both the rate and mechanism of tablet disintegration. Water-soluble fillers tend 
to dissolve rather than disintegrate, while insoluble diluents produce rapid disintegration. Lactose is a common tablet diluent, which exists in various grades differing in crystallinity and hydration and consequently in solubility. Contradicting results have been reported about the effect of lactose on the disintegration of tablets when used as a major component (Leskinen, 2003).

Figure 5 depicts the dissolution time of tablets made of different types of lactose. It is clear the superiority of SuperTab $21 \mathrm{AN}$ over other types of lactose to dissolve rapidly. In this case, using the conditions and equipment of the USP disintegration test. The next slower dissolution was displayed by Lactopress anhydrous, followed by SuperTab 24AN and lactose anhydrous NF.

In addition to physicochemical properties of a substance, some excipients may have an adverse effect on the dissolution rate. Lubricants such as stearates are hydrophobic in nature and can affect the wettability of a pharmaceutical product (Lee et al., 2008). Figure 5 shows the effect of stearic acid on the dissolution time of tablets made of different types of lactose. As expected, all studied lactose types show an increase in the time necessary for tablets dissolution. However, after lubrication SuperTab 24AN becomes the lactose type displaying the longest dissolution time.

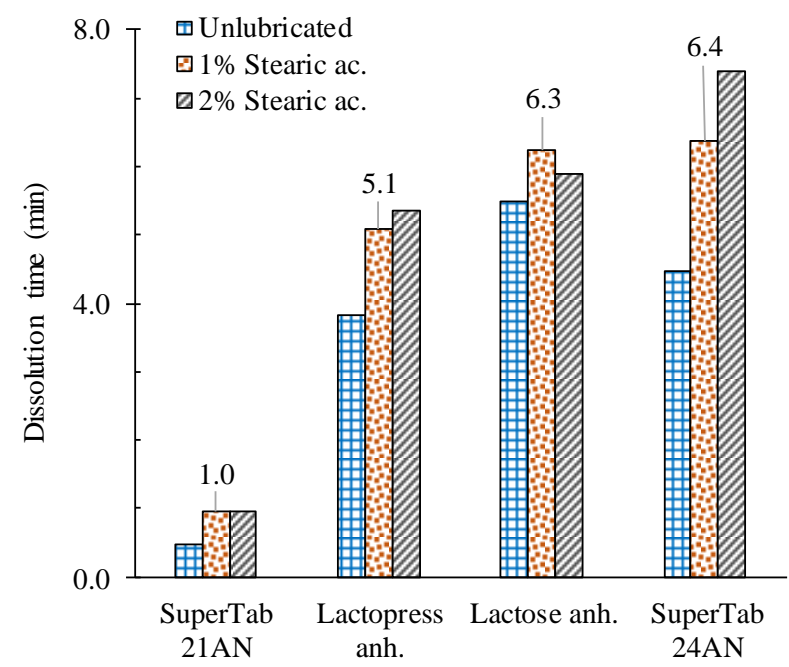

Fig. 5: Dissolution time of tablets of different types of lactose, unlubricated and lubricated with $1 \%$ and $2 \%$ stearic acid; under conditions and equipment of a disintegration test.

The higher dissolution time of SuperTab 24 AN tablets can be partially attributed to their higher compactibility. SuperTab 24AN tablets lubricated with $2 \%$ stearic acid and compacted at a pressure of $135 \mathrm{MPa}$ display a tablet hardness of $194 \mathrm{~N}$ while that of tablets of SuperTab 21AN attain only 110 N. Lactopress anhydrous and lactose NF anhydrous lay in between of SuperTabs (Velázquez-González et al., 2015). Figure 6 depicts the dissolution profiles of captopril tablets containing different types of lactose and $1 \%$ lubricant. The points are experimental and the lines are the calculated regressions. The faster dissolution is observed in mixtures with SuperTab 21AN while the slower was obtained with SuperTab 24AN. Lactose NF and Lactopress were in between.

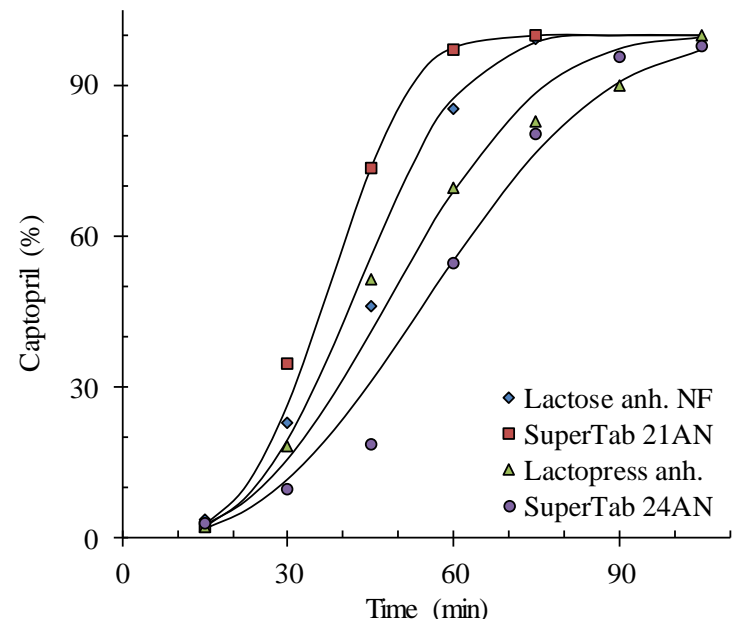

Fig. 6: Dissolution profile of captopril from tablets containing 50\% of different types of lactose. Experimental points and calculated regressions with a model based on the Weibull distribution.

Captopril displays a water solubility of $160 \mathrm{mg} / \mathrm{ml}$ at $25{ }^{\circ} \mathrm{C}$ (Captopril, 2015). In this way, the dissolution of $100 \mathrm{mg}$ in $900 \mathrm{ml}$ are considered to proceed under sink conditions.

The dissolution curves depicted in Figure 6 are in line with the dissolution time of tablets made of different types of lactose lubricated with stearic acid. The faster dissolving lactose tablets correspond with the faster captopril dissolution rate (SuperTab 21AN), while the slower dissolving tablets correspond with the slower drug dissolution rate (SuperTab 24AN). This can be ascribed in part to the fact that captopril/SuperTab 24AN tablets exhibit the higher tablet hardness $(118 \mathrm{~N})$ while captopril/ SuperTab 21AN displays the lower tablet hardness $(95 \mathrm{~N})$ (Velázquez-González et al., 2015).

In this circumstance and when using as dissolution conditions $30^{\circ} \mathrm{C}$ with a stirring rate of $20 \mathrm{rpm}$, the comparative dissolution profiles of captopril can be inferred from the dissolution of tablets of the excipients. The dissolution conditions were adjusted to reduce the dissolution rate in order to increase the discrimination capability of the test. The model used to describe the sigmoid dissolution profiles is based on the Weibull distribution:

$\ln (-\ln (1-\%$ Dis $/ 100))=n * \ln t+I \quad \ldots$ Eq. 2

Where \% Dis corresponds to the percentage drug dissolved at the time $t$ while $n$ and $I$ are the slope and the intercept of the regression line respectively. The application of this model to dissolution data of captopril tablets is depicted in Figure 7 and summarized in table 1 .

Table 1: Regression parameters of dissolution profiles of captopril tablets containing different types of lactose, according to: $\ln (-\ln (1-\%$ Dis/100)) $=$ Slope $* \ln t+$ Intercept .

\begin{tabular}{cccc}
\hline Lactose type & Slope & Intercept & $\mathbf{r}^{2}$ \\
\hline Lactose anh. NF & 3.239 & -12.51 & 0.971 \\
SuperTab 21AN & 3.588 & -13.38 & 0.993 \\
Lactopress anh. & 2.778 & -11.22 & 0.977 \\
SuperTab 24AN & 2.677 & -11.18 & 0.971 \\
\hline
\end{tabular}




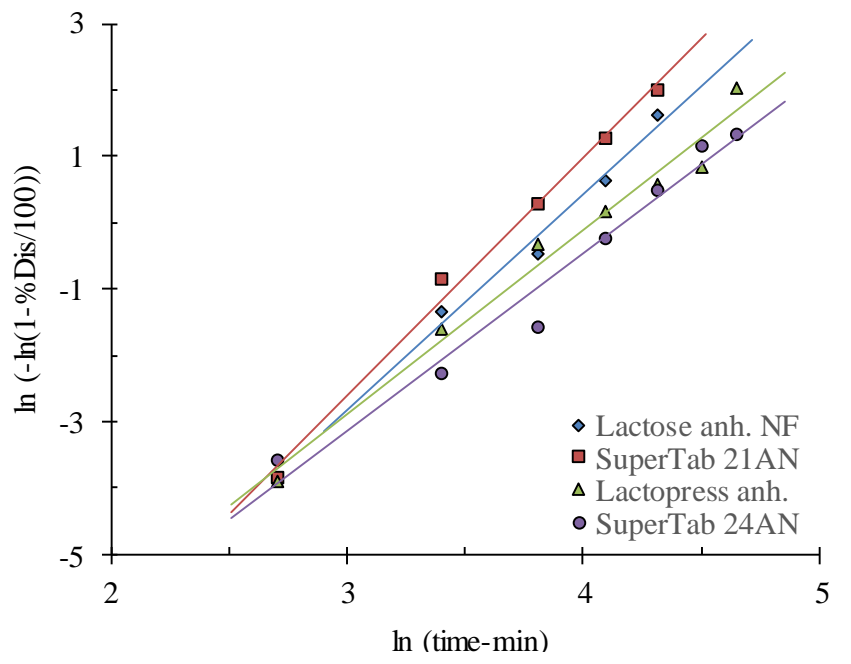

Fig. 7: Release profile of captopril tablets containing different types of lactose, according to: $\ln (-\ln (1-\%$ Dis/100 $))=$ Slope $* \ln t+$ Intercept .

As another application of different types of lactose and their effect on drug dissolution, Figure 8 depicts the dissolution profile of amoxicillin tablets containing different types of lactose, showing the experimental points and the calculated regressions. Amoxicillin displays a water solubility of $3.43 \mathrm{mg} / \mathrm{ml}$. In this way, the dissolution of $300 \mathrm{mg}$ in $900 \mathrm{ml}$ are considered to proceed under sink conditions (Ramos et al., 2015). In spite of an eventual reaction between amoxicillin and lactose, it was considered that this effect was a constant for all formulations and in this way, the comparative dissolution profiles are still useful to compare the effect of different types of lactose on release rate of amoxicillin (Gamble et al., 2010).

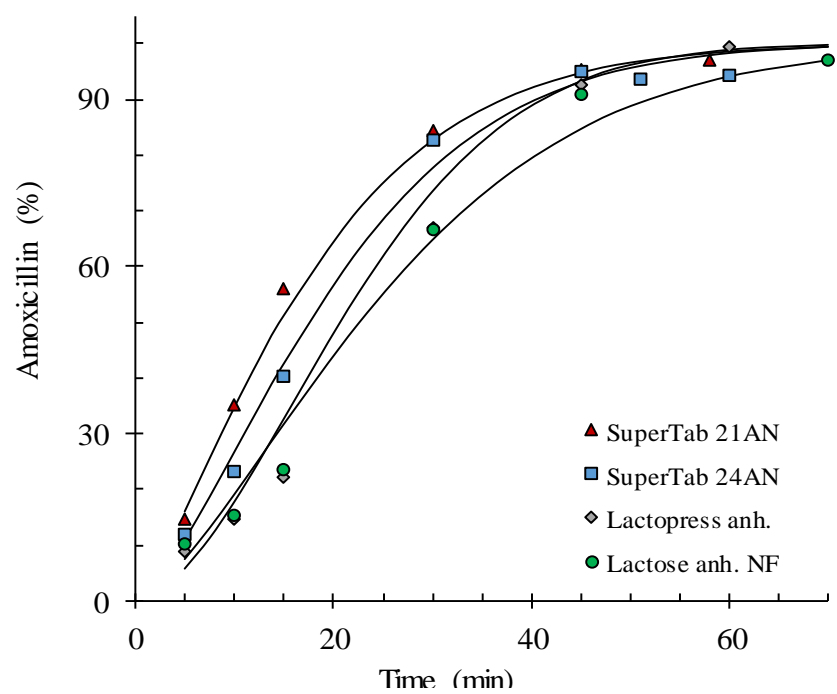

Fig. 8: Dissolution profile of amoxicillin from tablets containing $50 \%$ of different types of lactose. Experimental points and calculated regressions.

The slower dissolving excipient tablets (SuperTab 24AN) does not correspond with the slower amoxicillin dissolution profile. In this sense, the drug dissolution profile cannot inferred, comparatively, from the properties of the tablets of pure excipients. The dissolution behavior of the different types of lactose tablets and tablets containing $50 \%$ captopril or amoxicillin is comparatively depicted in Fig. 9. Pure lactose tablets are represented by the time necessary for their complete dissolution and the drug formulations by the calculated time necessary to dissolve $50 \%$ of the drug.

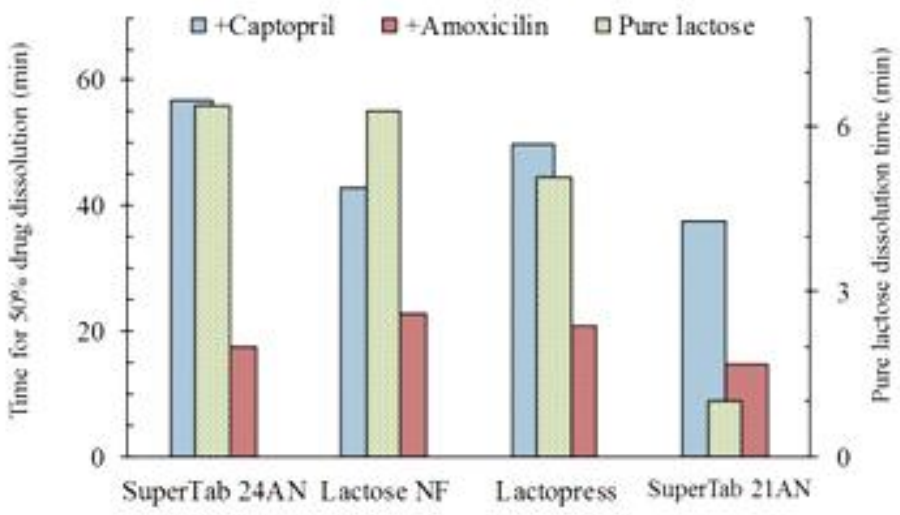

Fig. 9: Time necessary to dissolve $50 \%$ of the drug from tablets containing different types of lactose and $1 \%$ lubricant, compared with the time necessary to dissolve lactose tablets containing $1 \%$ lubricant.

As can be seen in Figure 9, dilution of the excipients with $50 \%$ of the drugs equalize the differences observed by tablets of pure excipients. Although more with amoxicillin than with captopril. Anyway, SuperTab $21 \mathrm{AN}$ is the excipient of choice to increase the dissolution rate of the studied drugs.

Although the dissolution behavior of the different types of lactose can be ascribed to their state of aggregation and their corresponding physicochemical properties, particularly the tablet hardness contributes to dissolution behavior. Figure 10 depicts the effect of the tablet hardness of the different types of lactose on the time necessary to complete dissolution of the pure excipients and the time necessary to dissolve $50 \%$ of the drug contained in the formulations with the different types of lactose. The physical properties of lactoses, expressed as compactibility contribute together with the solubility and dissolution rate to dissolution behavior (Velázquez-González at al., 2015). Harder tablets require progressive longer times for lactose and drug dissolution, independently of solubility and dissolution rate of the different types of lactose. Even if tablets of amoxicillin do not correlate in the same manner.

An original important difference in tablet hardness between SuperTab 21AN (119 N) and SuperTab 24AN (229 N) becomes a minor difference after dilution with $50 \%$ amoxicillin, $108 \mathrm{~N}$ and $148 \mathrm{~N}$ respectively (Velázquez-González et al., 2015). Dilution with amoxicillin shows an equalizing effect in compactibility of these different types of lactose. This behavior seems to be related to the own compactibility of amoxicillin. Thus, the dissolution rate is also equalized. 


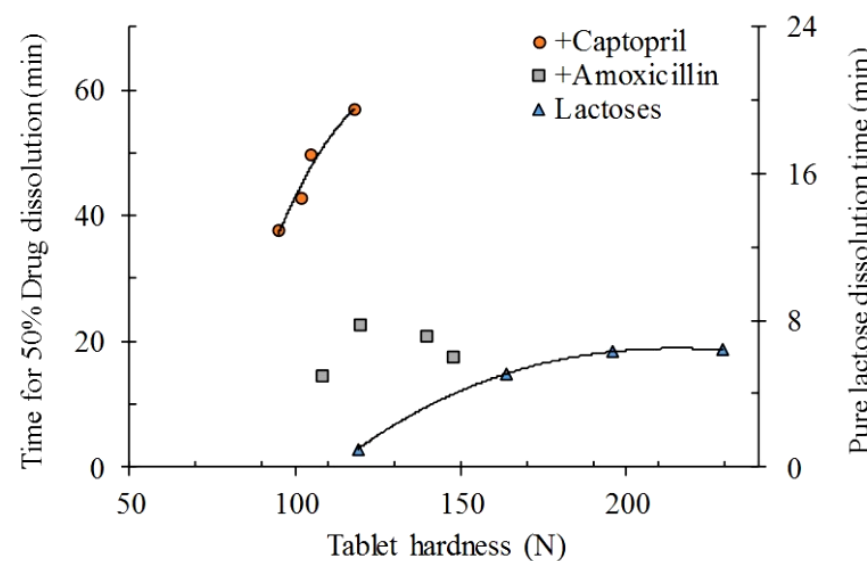

Fig. 10: Effect of tablet hardness on the required time for total dissolution of lactose tablets as well as on the time required to dissolve $50 \%$ of the drug in formulations of captopril and amoxicillin.

\section{CONCLUSION}

Quantification of powder flowability of different types of lactose, as excipients for direct compression, showed superiority of SuperTabs 21AN and 24AN over other types of lactose such as Lactopress anhydrous and lactose anhydrous NF. SuperTabs flow at least 20 times faster through a funnel than the other types of lactose. Lubrication of lactoses increases the flow rate, maintaining the comparative differences observed by the unlubricated ones. Similar results are observed when determining the powder compressibility. However, the differences are smaller. SuperTabs show an about $40 \%$ lower compressibility index than lactose anhydrous NF and Lactopress anhydrous. SuperTabs diplay a flowability allowing direct processing while Lactopress and lactose NF will need addition of a glidant.

Dilution of lactoses with $50 \%$ captopril or amoxicillin reduces drastically the powder flow through a funnel. The reduction being more important by admixture with amoxicillin than with captopril. Moreover, dilution display also an equalizing effect. The originally 20 times greater flowability of SuperTabs, compared to the other types of lactose, practically disappears after dilution. In the same way, the compressibility index of the different types of lactose increases 2-3 times when mixed with the drugs, displaying also a similar equalizing effect on the powder flowability.

Dissolution of lubricated and unlubricated lactose tablets show a faster dissolution of SuperTab 21AN tablets and a slower dissolution of SuperTab 24AN tablets, laying in between Lactopress and lactose NF tablets. As expected, lubrication of lactose increases the time to dissolve the tablets. The dissolution behavior could be attributed to differences in physicochemical properties such as solubility and dissolution of the different presentations of lactose. However, in this case the differences in mechanical properties of the tablets contribute in an important manner. Tablets made of Supertab 21AN display the lower tablet hardness and the faster dissolution. Correspondingly, SuperTab 24AN displays the higher tablet hardness and the slower dissolution. Dilution of lactoses with $50 \%$ captopril displays a quite smaller dissolution rate with a comparative similar behavior as tablets of the excipients. SuperTab 21AN/captopril tablets display the faster dissolution rate while SuperTab 24AN/captopril tablets display the slower one. Lactopress/captopril tablets and lactose NF/captopril tablets lay in between. Lactoses dilution with amoxicillin show an equalizing effect of the drug dissolution behavior, displaying only minor differences. The effect of lactose excipients on dissolution seems to be more related with the tablets mechanical properties such as tablet hardness than a particular difference in solubility and dissolution rate.

\section{REFERENCES}

Aleeva GN, Zhuravleva MV, Khafiz'yanova RK. Studies of the structure of chemical compounds, analytical methods and production monitoring the role of excipients in determining the pharmaceutical and therapeutic properties of medicinal agents (review). Pharm Chem J, 2009; 43 (4): 230-234

Al-Khedairy EBH. Effect of additives on the solubility and dissolution of piroxicam from prepared hard gelatin capsule. Iraqi J Pharm Sci, 2012; 21(1):117-122

Allahham A, Stewart PJ. Enhancement of the dissolution of indomethacin in interactive mixtures using added fine lactose. Eur $\mathrm{J}$ Pharm Biopharm, 2007; 67 (3): 732-742.

Captopril (CAS 62571-86-2). Santa Cruz Biotechnology Inc. Available at: http://www.scbt.com/es/datasheet-200566-captopril.html [Accessed on 09 March 2015].

Choi DH, Kim NA, Chu KR, Jung YJ, Yoon JH, Jeong SH. Material properties and compressibility using Heckel and Kawakita equation with commonly used pharmaceutical excipients. J Pharma Inv, 2010; 40 (4): 237-244.

DFE pharma. Technical papers. Use of lactose in hard gelatin capsules. Available at: http://www.dfepharma.es/es-es /knowledge-base/documentation/technical-documents/downloadpapers.aspx. [Accessed 17 March 2015].

Dickinson PA, Lee WW, Stott PW, Townsend AI, Smart JP Ghahramani P, Hammett T, Billett L, Ryan SB, Gibb C, Abrahamsson B. Clinical relevance of dissolution testing in quality by design. The AAPS Journal, 2008; 10 (2): 280-290.

Dredan J, Antal I, Racz I, Marton S. Interfacial behaviour of pharmaceutical excipients. Progr Colloid Polym Sci, 2004; 125: 111-116.

Emshanova SE. Drug synthesis methods and production technologies methodological approaches to the selection of excipients for preparation of tablets by direct pressing. Pharm Chem J, 2008; 42 (2): 89 94.

Fuentes González KI, Villafuerte Robles L. Powder flowability as a functionality parameter of the excipient GalenIQ 720. Int J Pharm Pharm Sci, 2014; 6 (9): 66-74.

Gamble JF, Chiu WS, Gray V, Toale H, Tobyn M, Wu Y. Investigation into the degree of variability in the solid-state properties of common pharmaceutical excipients-anhydrous lactose. AAPS PharmSciTech, 2010;11 (4).

Kubbinga M, Moghani L, Langguth P. Novel insights into excipient effects on the biopharmaceutics of APIs from different BCS classes: Lactose in solid oral dosage forms. Eur J Pharm Scie, 2014; 61 (30): 27-31.

Lee SL, Poynter R, Podczeck F, Newton JM. Development of a dual approach to assess powder flow from avalanching behavior. AAPS PharmSciTech, 2000; 1 (3).

Lee, S.L., Raw, A.S., Yu, L. 2008. Dissolution testing. In Biopharmaceutics application in drug development. Krishna R. \& Yu L. editors. Springer Science + Business media, LLC. pp 47-74.

Leskinen E. 2003. Seminar summary division of pharmaceutical technology department of pharmacy University of Helsinki, 31.3.2003 Tablet disintegration: Effects of temperature and $\mathrm{pH}$ of aqueous 
disintegrating fluid and influence of solubility of diluent on the behaviour of superdisintegrants. Available at: http://www.pharmtech.helsinki.fi/ seminaarit/vanhat/eijaleskinen.pdf [Accessed 29 April 2015].

Podczeck, F., Miah, Y. The influence of particle size and shape on the angle of internal friction and the flow factor of unlubricated and lubricated powders. Int J Pharm, 1996; 144: 187194.

Ramos F, Boison J, Friedlander LG. Amoxicillin- FAO.org. Available at: http://www.drugfuture.com/chemdata/amoxicillin.html [Accessed 12 March 2015].

Räsänen E, Antikainen O, Yliruusi J. A New method to predict flowability using a microscale fluid bed. AAPS PharmSciTech 2003, 4 (4) Article 53.

SuperTab 24AN, Agglomerated anhydrous lactose. Available at: http://www.excipient.ru/uploads/files/SuperTab_24AN_v2.pdf. [Accessed 17 March 2015].
Zhou, Q., Armstrong, B., Larson, I., Stewart, P. J. Improving powder flow properties of a cohesive lactose monohydrate powder by intensive mechanical dry coating. J Pharm Sci, 2009; 99(2): 969-81.

\section{How to cite this article:}

Karen Velázquez-González, Eduardo Ramírez-Flores, Leopoldo Villafuerte-Robles. Influence of different types of lactose on powder flow and tablets dissolution. J App Pharm Sci, 2015; 5 (09): 089-096. 